\title{
Low serum 25-hydroxyvitamin D levels are associated with liver injury markers in the US adult population
}

\author{
Xiaowei He ${ }^{1,} \uparrow$, Cheng X $u^{2,3} \uparrow$, Zheng-Hong $\mathrm{Lu}^{4}$, Xiao-Zheng Fang ${ }^{4}$, Juan Tan ${ }^{4 *}$ and \\ Yingiian Song ${ }^{5, *}$ \\ 'Department of Endocrinology and Metabolism/Diabetes Care and Research Center, Nanjing Medical University \\ Affiliated Geriatric Hospital/Jiangsu Province Geriatric Hospital, Jiangsu Province Official Hospital/Jiangsu Province \\ Institute of Geriatrics, Nanjing, People's Republic of China: ${ }^{2}$ State Key Laboratory of Reproductive Medicine, School of \\ Public Health, Nanjing Medical University, Nanjing, People's Republic of China: ${ }^{3}$ Key Laboratory of Modern \\ Toxicology of Ministry of Education, Center for Global Health, Nanjing Medical University, Nanjing, People's Republic \\ of China: ${ }^{4}$ Department of Gerontology, The Affiliated Huaian No. 1 People's Hospital of Nanjing Medical University, \\ Huai'an, Jiangsu 223300, People's Republic of China: ${ }^{5}$ Department of Respiratory Medicine, The Affiliated Huaian \\ No. 1 People's Hospital of Nanjing Medical University, Huai'an 223300, People's Republic of China
}

Submitted 21 June 2019: Final revision received 21 December 2019: Accepted 20 January 2020: First published online 24 June 2020

\begin{abstract}
Objective: To examine the associations between serum 25-hydroxyvitamin D $(25(\mathrm{OH}) \mathrm{D})$ levels and serum liver enzymes in a representative sample of US adults. Design: The cross-sectional study sample consisted of 24229 adults with data on serum 25(OH)D levels and serum alanine aminotransferase (ALT), aspartate aminotransferase (AST), alkaline phosphatase (ALP) and gamma-glutamyl transaminase (GGT) concentrations, in addition to data on other potential confounders. Multivariate logistic regression and linear regression were applied to assess the associations between serum 25(OH)D levels and ALT, AST, ALP and GGT concentrations.

Setting: The National Health and Nutrition Examination Survey, 2001-2006.

Participants: The cross-sectional study sample consisted of 24229 adults.

Results: We found a significant association between low serum 25(OH)D levels $(<30 \mathrm{nmol} / \mathrm{l})$ and ALP levels in all participants (OR 2.67; 95\% CI 1.98, 3.59; $P<0.001$ ), a confirmed healthy population (OR 3.02; $95 \%$ CI $2.25,4.07 ; P<0.001$ ) and individuals with viral hepatitis (OR 2.87; $95 \%$ CI 1.52, 5.44; $P=0.006$ ) compared with those who had normal 25(OH)D levels $(>50 \mathrm{nmol} / \mathrm{l})$. Moreover, in both the logistic regression and linear regression, the associations between $25(\mathrm{OH}) \mathrm{D}$ levels and ALP levels were stronger in the subgroups with obesity. No association was present between ALT, AST or GGT levels and serum 25(OH)D levels in this population.

Conclusions: The results of the present study provide epidemiological evidence that vitamin D deficiency is associated with liver ALP levels in humans. This finding suggests a potential adverse effect of low 25(OH)D levels on human liver function. However, the underlying mechanisms still need further investigation.
\end{abstract}

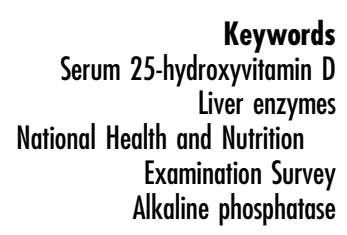

Vitamin D, a fat-soluble secosteroid, has crucial roles mainly in accelerating intestinal absorption in humans ${ }^{(1)}$. Under normal physiological conditions, vitamin $\mathrm{D}$ is transported from the blood to the liver tissue, is further hydroxylated to form 25-hydroxyvitamin D (25(OH)D) in the liver and is finally released into the blood.

†These authors contributed equally to the present study and should be regarded as joint first authors.
In addition to its traditional skeletal adverse effect $^{(2)}$, vitamin $\mathrm{D}$ deficiency has been now recognised to exert abnormal biological effects on several other organ systems (e.g. cardiovascular risk $^{(3)}$, diabetes ${ }^{(4)}$, metabolic syndrome ${ }^{(5)}$, some common cancers and autoimmune diseases $^{(6)}$ ) in humans. Recently, some studies have found that vitamin D deficiency is common in patients with chronic liver disease and vitamin D levels are inversely correlated with the severity of chronic liver 
disease $\mathrm{e}^{(7,8)}$. For instance, epidemiological studies have found that non-alcoholic fatty liver disease patients have a marked decrease in serum $25(\mathrm{OH}) \mathrm{D}$ concentrations ${ }^{(9)}$. In addition, lower vitamin D status in patients is closely associated with histopathological features of nonalcoholic fatty liver disease ${ }^{(10)}$. These results suggest potential associations between 25(OH)D levels and liver function. However, currently the information on associations between vitamin D status and liver enzymes is lacking.

Herein, we performed the first cross-sectional study exploring the relationship between serum 25(OH)D levels and serum levels of four enzymes commonly used in liver function tests (alanine aminotransferase, aspartate aminotransferase, alkaline phosphatase (ALP), and gammaglutamyl transaminase (GGT)) in US adults. Elucidation of these relationships may be of clinical importance in formulating preventative or therapeutic strategies for liver dysfunction.

\section{Method}

\section{Study population}

The National Health and Nutrition Examination Survey (NHANES), a study of a nationally representative sample of the US population ${ }^{(11)}$, was conducted by the National Center for Health Statistics of the Centers for Disease Control and Prevention. A detailed description of the study design has been published elsewhere ${ }^{(12,13)}$. To explore whether a potential relationship is present between low $25(\mathrm{OH}) \mathrm{D}$ levels and serum hepatic enzyme levels in adults, we used a database including all available serum $25(\mathrm{OH}) \mathrm{D}$ levels from 2001 to 2006. We excluded data from participants who lacked serum 25(OH)D levels and liver enzyme concentrations, those who were pregnant, those younger than 18 years old or those who reported suffering from osteoporosis. The final sample included 24229 participants. The study was approved by the National Center for Health Statistics Research Ethics Review Board.

\section{Assessment of serum 25-bydroxyvitamin D levels}

The DiaSorin RIA kit was used to measure serum 25(OH)D concentrations from the NHANES 2001-2006 at the National Center for Environmental Health. A detailed description is available on the website ${ }^{(14)}$. It is noteworthy that before October 2015, there was excessive method bias and imprecision in the methods used to measure $25(\mathrm{OH}) \mathrm{D}$ levels in the NHANES. Thus, a model according to RIA quality control pool data was selected based on the idea that the results should be independent of any empirical trend in the sample participant data ${ }^{(15)}$. As a consequence, the 25(OH)D data from the NHANES 2003-2004 and 2005-2006 were generally adjusted to lower and higher values, respectively ${ }^{(15)}$. According to the Institute of Medicine report defining vitamin D deficiency and insufficiency in the USA ${ }^{(16)}$, the three categories of deficiency were as follows: (a) adequate vitamin $\mathrm{D}$ level (serum $25(\mathrm{OH}) \mathrm{D} \geq 50 \mathrm{nmol} / \mathrm{l}$ ), (b) insufficient vitamin $\mathrm{D}$ level (serum $25(\mathrm{OH}) \mathrm{D} \geq$ $30 \mathrm{nmol} / \mathrm{l}$ but below $50 \mathrm{nmol} / \mathrm{l}$ ) and (c) deficient vitamin D level (serum 25(OH)D $<30 \mathrm{nmol} / \mathrm{l}$ ).

\section{Liver enzyme measurement}

Serum biochemical parameters, such as alanine aminotransferase, aspartate aminotransferase, ALP and gammaglutamyl transaminase, were measured using a Hitachi model 704 multichannel analyser in 2001-2002. Starting in 2003, NHANES used the Beckman Synchron LX20 analyser to detect the biochemistry profile. Although two different test methods are presented in our data, the distribution of the liver enzyme levels was nearly identical in the whole study period 2001-2006. As a consequence, cut-off points were recommended in 2001-2010 to define an abnormal status of alanine aminotransferase ( $>47 \mathrm{IU} / 1$ in men or $>30 \mathrm{IU} / 1$ in women), aspartate aminotransferase ( $>33$ IU/1 in men and women), ALP (>113 IU/1 in men and women) and gamma-glutamyl transaminase (>65 IU/1 in men or $>36 \mathrm{IU} / 1$ in women). ${ }^{(17)}$

\section{Covariates}

A wide range of sociodemographic variables was collected during the NHANES 2001-2006, such as age, gender, race and ethnicity, education and poverty-income ratio. Behavioural risk factors, such as alcohol drinking, were obtained from the questionnaire. In addition, NHANES participants reported medical conditions, including osteoporosis. BMI (body weight divided by height squared, $\mathrm{kg} / \mathrm{m}^{2}$ ) was measured by trained examiners. Serum cotinine levels, a marker of smoking status, were measured from laboratory examinations. Additionally, hepatitis B infection status (infection defined as surface antigen- or core antibodypositive) and hepatitis $\mathrm{C}$ infection status (infection defined as antibody-positive) were obtained from laboratory examinations.

\section{Statistical methods}

To investigate the relationship between serum 25(OH)D concentrations and abnormal liver enzyme levels, we used weighted multiple variable logistic regression and listed the associations with the OR and $95 \% \mathrm{CI}$, as well as the interaction between gender, BMI, alcohol consumption and the categories of serum $25(\mathrm{OH}) \mathrm{D}$ levels. The associations between serum $25(\mathrm{OH}) \mathrm{D}$ concentrations and continuous enzyme levels were assessed using weighted multiple variable linear regression models. We calculated two multivariate adjusted geometric means and $95 \% \mathrm{CI}$ of liver enzyme levels by categories of serum $25(\mathrm{OH}) \mathrm{D}$ levels. As liver enzyme levels are influenced by patients' hepatitis condition, we conducted separate analyses stratified by hepatitis status. The unadjusted and two multivariate models were conducted after adjusting for model a, which 
encompassed age, gender, race and ethnicity, and model b, which included age, gender, race and ethnicity, education, BMI, cotinine, alcohol intake and poverty-income ratio. The highest level (adequate concentration) was used as the reference value. In addition, we performed a test for the trend of the OR to assess the association between elevated liver enzyme levels and 25(OH)D levels and $25(\mathrm{OH}) \mathrm{D}$ coded as an ordinal variable. Moreover, we present the magnitudes of association as the average percentage difference in liver enzyme levels for an interquartile (75th/25th percentiles) contrast of serum vitamin D, calculated as ((interquartile ratio $\left.\left.\wedge^{\text {Beta }}\right)-1\right) \times 100$. Confirmed healthy population refers to those who are negative for hepatitis $\mathrm{B}$ and hepatitis $\mathrm{C}$ antibodies and those who chose 'No' to the questionnaire question related to 'any liver condition'. Then, according to whether or not the individual drank, the group was further divided into a non-alcoholic healthy population and an alcoholic healthy population. The subjects who were positive for hepatitis $\mathrm{B}$ and hepatitis $\mathrm{C}$ antibodies were categorised as viral hepatitis. The above statistical analyses were performed with the Statistical Analysis Software package, version 9.2 (SAS Institute, Inc.). A $P$ value $<0.05$ was designated as the cut-off for statistical significance.

\section{Result}

The final analytic population included 24229 participants (12 487 males and 11742 females; Fig. 1). Table 1 presents the baseline characteristics and mean concentrations of serum 25(OH)D, alanine aminotransferase, aspartate aminotransferase, ALP and gamma-glutamyl transaminase levels (adequate, inadequate and deficient status) among the participants included in the present study from the NHANES 2001-2006 database. Overall, female (59.0\%), non-Hispanic black (57.3\%) and obese ( $45.9 \%)$ participants represented the greatest proportion of vitamin D-deficient individuals in the sample.

Considering that osteoporosis and age may be confounding factors, we excluded people who had osteoporosis. At the same time, we present the relationship between age and ALP, and the proportion of vitamin D deficiency in the elderly population was not larger than that in the other subgroups in our study (Supplemental Fig. 1).

A scatter diagram showed an approximately inverse relationship between log-transformed 25(OH)D levels and log-transformed ALP levels (Fig. 2). We further found that lower $25(\mathrm{OH}) \mathrm{D}$ levels were associated with higher odds of abnormal ALP (Table 2), and the results were largely similar after adjusting for the two models. Compared to those with adequate $25(\mathrm{OH}) \mathrm{D}$ concentrations, those who had inadequate and deficient statuses had an OR of 1.41 (95\% CI 1.12, 1.77) and $2.67(95 \%$ CI 1.98, 3.59), respectively, for abnormal levels of ALP, while the other three liver enzymes were not significantly different in model b. According to a previous study, liver enzyme levels are affected by alcohol intake and hepatitis status ${ }^{(17)}$. In our study, negative results were found in both the non-alcoholic healthy population and alcoholic healthy population. In the viral hepatitis subgroup

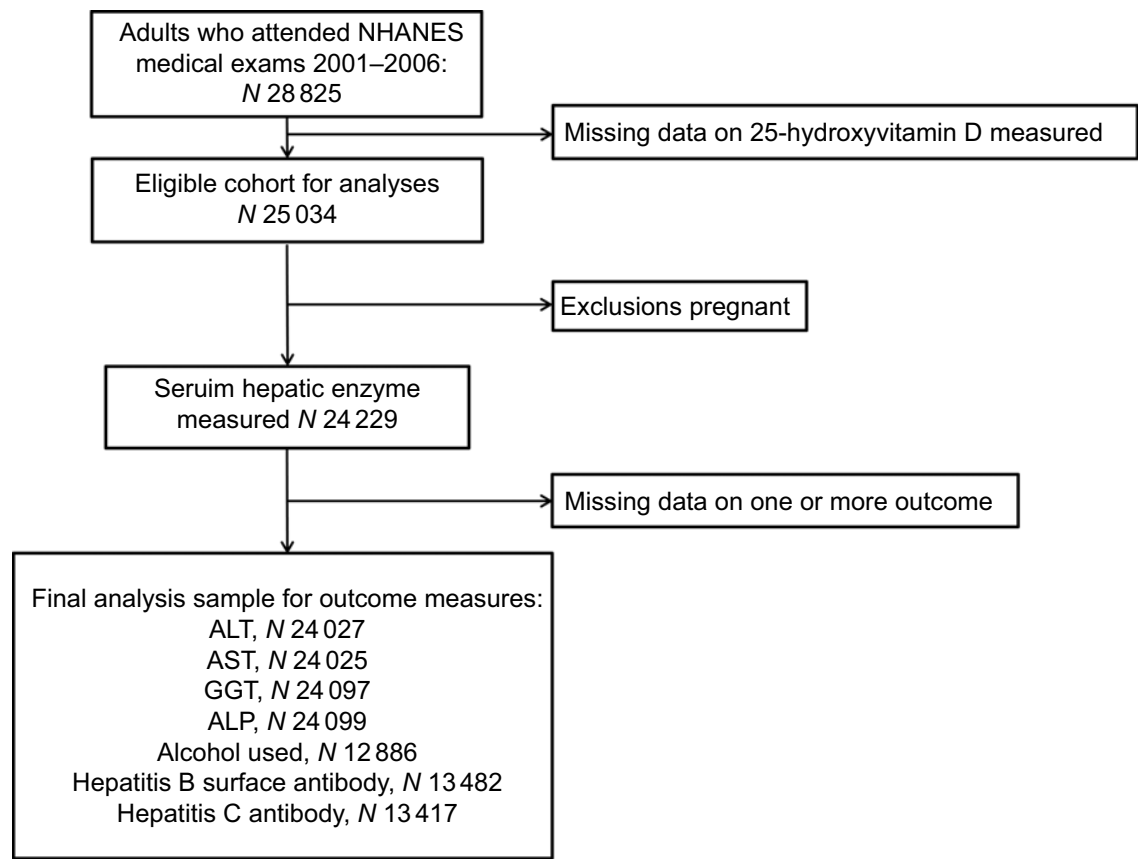

Fig. 1 Eligible participants and those included in the analyses of the associations between serum 25-hydroxyvitamin D and alkaline phosphatase (ALP) in adults. NHANES, National Health and Nutrition Examination Survey; ALT, alanine aminotransferase; AST, aspartate aminotransferase; GGT, gamma-glutamyl transaminase 
Table 1 Selected characteristics of study sample by serum 25-hydroxyvitamin D (25(OH)D) category in adults, National Health and Nutrition Examination Survey (NHANES) (2001-2006)

\begin{tabular}{|c|c|c|c|c|c|c|c|c|c|c|}
\hline \multirow{3}{*}{ Characteristics* } & \multicolumn{9}{|c|}{ Serum $25(\mathrm{OH}) \mathrm{D}$} & \multirow{3}{*}{$P$ values } \\
\hline & \multicolumn{3}{|c|}{$\begin{array}{c}\text { Adequate }(>50 \mathrm{nmol} / \mathrm{l}) \\
(n 14971)\end{array}$} & \multicolumn{3}{|c|}{$\begin{array}{c}\text { Inadequate }(30-50 \mathrm{nmol} / \mathrm{l}) \\
(n 6904)\end{array}$} & \multicolumn{3}{|c|}{$\begin{array}{c}\text { Deficient }(<30 \mathrm{nmol} / \mathrm{l}) \\
(n 2354)\end{array}$} & \\
\hline & Mean & $\%$ & SD & Mean & $\%$ & SD & Mean & $\%$ & SD & \\
\hline Age (years) & $48 \cdot 7$ & & $19 \cdot 4$ & $45 \cdot 6$ & & $19 \cdot 3$ & $43 \cdot 9$ & & 19.5 & $<0.001$ \\
\hline Vitamin D (nmol/l) & $73 \cdot 1$ & & $18 \cdot 8$ & $40 \cdot 4$ & & 5.9 & 23.4 & & 4.6 & $<0.001$ \\
\hline $\mathrm{ALT}(\mathrm{U} / \mathrm{I})$ & $25 \cdot 6$ & & $24 \cdot 3$ & $26 \cdot 4$ & & 31.9 & 23.4 & & $17 \cdot 2$ & $<0.001$ \\
\hline AST $(U / I)$ & $25 \cdot 7$ & & 14.7 & $26 \cdot 1$ & & $27 \cdot 2$ & $25 \cdot 6$ & & $18 \cdot 6$ & $<0.001$ \\
\hline ALP $(U / /)$ & $69 \cdot 2$ & & 23.9 & $73 \cdot 2$ & & $24 \cdot 1$ & 77.5 & & 41.6 & $<0.001$ \\
\hline GGT (U/I) & $28 \cdot 1$ & & $35 \cdot 2$ & 31.4 & & $50 \cdot 6$ & 34.0 & & 65.0 & $<0.001$ \\
\hline Alcohol intake per d (g) & $12 \cdot 1$ & & $32 \cdot 6$ & $9 \cdot 1$ & & $27 \cdot 2$ & $9 \cdot 3$ & & $30 \cdot 3$ & $<0.001$ \\
\hline Gender & & & & & & & & & & $<0.001$ \\
\hline Male & \multicolumn{3}{|c|}{53.9} & \multicolumn{3}{|c|}{$50 \cdot 1$} & \multicolumn{3}{|c|}{41.0} & \\
\hline Female & \multicolumn{3}{|c|}{$46 \cdot 1$} & \multicolumn{3}{|c|}{49.9} & \multicolumn{3}{|c|}{$59 \cdot 0$} & \\
\hline Race and ethnicity & & & & & & & & & & $<0.001$ \\
\hline Mexican American & \multicolumn{3}{|c|}{$17 \cdot 3$} & \multicolumn{3}{|c|}{$27 \cdot 2$} & \multicolumn{3}{|c|}{17.9} & \\
\hline Other Hispanic & \multicolumn{3}{|c|}{$6 \cdot 7$} & \multicolumn{3}{|c|}{7.5} & \multicolumn{3}{|c|}{4.8} & \\
\hline Non-Hispanic White & \multicolumn{3}{|c|}{63.0} & \multicolumn{3}{|c|}{$28 \cdot 3$} & \multicolumn{3}{|c|}{$15 \cdot 0$} & \\
\hline Non-Hispanic Black & & 9.4 & & & 31.6 & & & $57 \cdot 3$ & & \\
\hline Other race & & 3.6 & & & 5.4 & & & $5 \cdot 0$ & & \\
\hline Education levels & & & & & & & & & & $<0.001$ \\
\hline$<9$ th grade & & 11.5 & & & 14.6 & & & 11.0 & & \\
\hline 9th-11th grade & & $12 \cdot 9$ & & & $16 \cdot 7$ & & & $18 \cdot 7$ & & \\
\hline High school/GED & & $22 \cdot 6$ & & & $20 \cdot 4$ & & & 21.8 & & \\
\hline Some college or AA degree & & $25 \cdot 5$ & & & $24 \cdot 0$ & & & $24 \cdot 3$ & & \\
\hline College and higher & & $21 \cdot 0$ & & & 13.9 & & & 11.3 & & \\
\hline BMI & & & & & & & & & & $<0.001$ \\
\hline$<25 \mathrm{~kg} / \mathrm{m}^{2}$ & & 34.5 & & & $26 \cdot 5$ & & & $25 \cdot 9$ & & \\
\hline $25-30 \mathrm{~kg} / \mathrm{m}^{2}$ & & 35.6 & & & 31.9 & & & 24.9 & & \\
\hline$>30 \mathrm{~kg} / \mathrm{m}^{2}$ & & $28 \cdot 2$ & & & $39 \cdot 1$ & & & 45.9 & & \\
\hline Serum cotinine & & & & & & & & & & $<0.001$ \\
\hline$<0.01 \mathrm{ng} / \mathrm{ml}(\mathrm{LOD})$ & & $61 \cdot 8$ & & & $56 \cdot 8$ & & & $48 \cdot 8$ & & \\
\hline $0.01-10 \mathrm{ng} / \mathrm{ml}$ & & $12 \cdot 8$ & & & $15 \cdot 2$ & & & $19 \cdot 2$ & & \\
\hline$>10 \mathrm{ng} / \mathrm{ml}$ & & $25 \cdot 1$ & & & $27 \cdot 7$ & & & $31 \cdot 7$ & & \\
\hline Alcohol use $(g / d)$ & & & & & & & & & & $<0.001$ \\
\hline 0 & & 72.5 & & & $78 \cdot 6$ & & & $80 \cdot 2$ & & \\
\hline $0.01-4.9$ & & 19.5 & & & $15 \cdot 0$ & & & $13 \cdot 0$ & & \\
\hline $5-14.9$ & & 6.8 & & & 5.6 & & & $5 \cdot 6$ & & \\
\hline $15-29.9$ & & 1.0 & & & 0.7 & & & $1 \cdot 1$ & & \\
\hline$\geq 30$ & & 0.1 & & & 0.1 & & & 0.1 & & \\
\hline $\mathrm{PI} \bar{R}$ & & & & & & & & & & $<0.001$ \\
\hline$\leq 1$ & & $16 \cdot 8$ & & & $22 \cdot 8$ & & & $25 \cdot 5$ & & \\
\hline$>1$ & & $76 \cdot 6$ & & & 69.6 & & & 67.3 & & \\
\hline Hepatitis B surface antibody & & & & & & & & & & 0.003 \\
\hline Positive & & $10 \cdot 8$ & & & $13 \cdot 0$ & & & $14 \cdot 2$ & & \\
\hline Hepatitis $\mathrm{C}$ antibody & & & & & & & & & & 0.585 \\
\hline Positive & & 1.0 & & & $1 \cdot 1$ & & & 1.3 & & \\
\hline
\end{tabular}

ALT, alanine aminotransferase; AST, aspartate aminotransferase; ALP, alkaline phosphatase; GGT, gamma-glutamyl transaminase; GED, General Educational Development; AA, Associate in Arts; LOD, limit of detection; PIR, poverty-income ratio.

*Weighted percentage.

analysis, an abnormal level of ALP was inversely associated with low 25(OH)D levels in both the confirmed healthy subpopulation $\left(\mathrm{OR}_{\text {deficient } v}\right.$. adequate $3.02,95 \%$ CI 2.25, 4.07; $\left.P_{\text {for trend }}<0.001\right)$ and in the viral hepatitis subpopulation ( $\mathrm{OR}_{\text {inadequate }} v$ adequate $2 \cdot 13,95 \%$ CI $1 \cdot 34$, 3.39; OR deficient $v$ adequate $2 \cdot 87,95 \%$ CI $1.52,5.44$; $\left.P_{\text {for trend }}: 0.006\right)$.

For each doubling to tripling (interquartile ratio contrast) in serum vitamin D levels, the percentage difference in ALP levels in the various groups ranged from -3.8 to $-5.3 \%$ (entire sample), -3.3 to $-5.1 \%$ (confirmed healthy),
-3.9 to $-8.4 \%$ (non-alcoholic healthy), -0.7 to $-7.2 \%$ (alcoholic healthy) and $-3 \cdot 7$ to $-7.4 \%$ (viral hepatitis) (Fig. 3).

In the subgroup analysis by gender, BMI and alcohol intake, the inverse association between low serum 25(OH)D concentrations and abnormally high OR of ALP levels appeared to be somewhat stronger among those who were male, obese and drank alcohol (Supplemental Fig. 2). Similar to the interquartile ratio-contrasting serum vitamin D levels, the percentage difference in ALP levels in the sample ranged from -3.5 to $-5.3 \%$ in the different subgroup analyses (Supplemental Fig. 3). However, there 
25(OH)D was associated with ALP

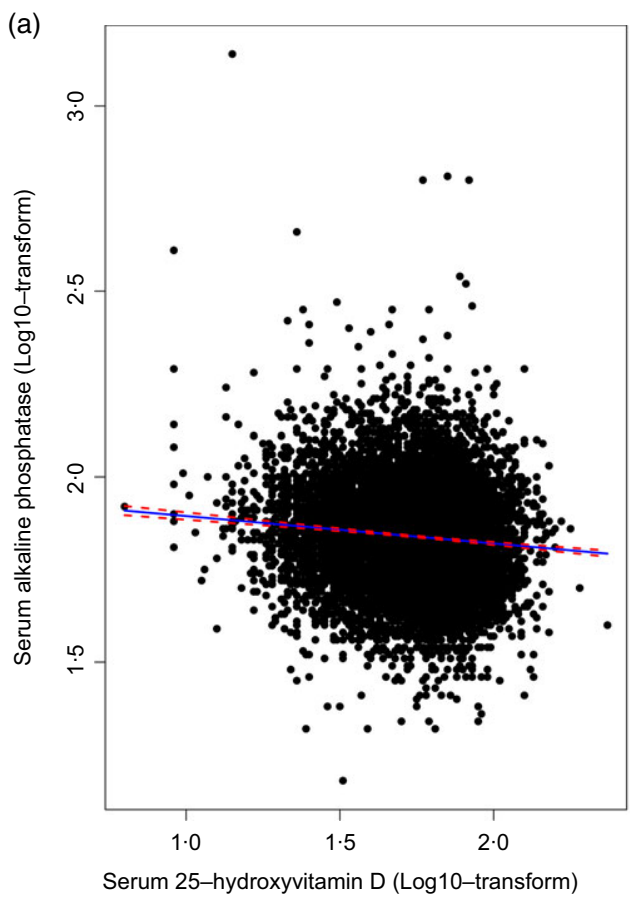

Fig. 2 (colour online) Scatter plot and a fitted line with a $95 \% \mathrm{Cl}$ of the relationship between serum 25-hydroxyvitamin D and alkaline phosphatase in males (a) and females (b)

were no significant interactions between serum 25(OH)D levels and gender, BMI, alcohol consumption for the ALP levels in either the logistic regression model or linear regression model.

\section{Discussion}

In this large sample of US adults, we first found that low serum $25(\mathrm{OH}) \mathrm{D}$ levels were inversely associated with a higher risk of having abnormal levels of liver enzymes, mainly ALP. Inverse associations with liver enzymes largely persisted in participants with viral hepatitis. In addition, stronger associations were found between $25(\mathrm{OH}) \mathrm{D}$ and ALP among individuals who were male, obese and drank alcohol habitually.

Among all commonly measured enzymes in the liver function tests, ALP has been less extensively studied. From a traditional perspective, serum ALP has mostly been reported to be associated with osteoporosis. Although we excluded participants with osteoporosis, age may be another influencing factor that is highly correlated with osteoporosis. However, in the present study, we found that the prevalence of vitamin D deficiency did not increase with age. Thus, age was not the main factor affecting the relationship between vitamin D and ALP in our study.

Previous epidemiological studies have shown that there is no difference in ALP levels between those with and without 25(OH)D deficiency among a Pakistan population ${ }^{(18)}$. Similarly, results among Australians showed that there were no differences in ALP levels among different

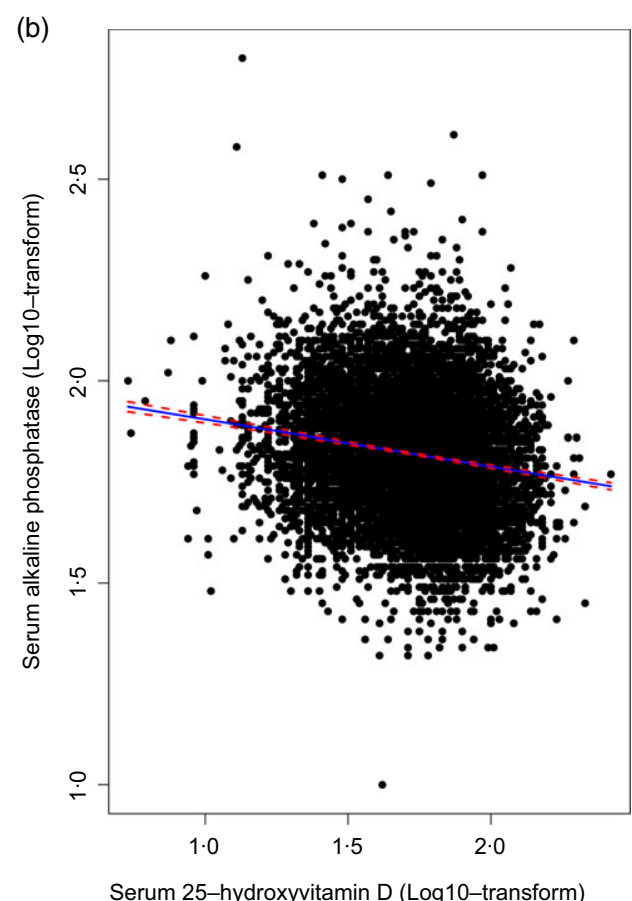

vitamin D concentration classifications. Further, there was no difference in ALP levels between the vitamin D supplement group and the placebo group ${ }^{(19)}$. It is worth mentioning that the sample size of the above studies was small. A meta-analysis showed that vitamin D supplementation reduces ALP levels in people with nonalcoholic fatty liver disease ${ }^{(20)}$. In addition, one study showed that maternal vitamin D deficiency can cause increased ALP levels in offspring $^{(21)}$. Jesudason et al. reported that vitamin D insufficiency is inversely related to serum ALP in postmenopausal women ${ }^{(22)}$. Our results are consistent with previous studies, but the associations are presented in general adults. Welz et al. ${ }^{(23)}$ found that HIV-infected patients who were treated with efavirenz had severe vitamin D deficiency and increased ALP levels simultaneously. Although the authors did not explain the coexistence of vitamin D deficiency and increased ALP levels, several studies have suggested that efavirenz leads to hepatotoxicity in humans ${ }^{(24,25)}$ and slight bone toxicity ${ }^{(26)}$. Thus, it is essential to explore the relationships between $25(\mathrm{OH}) \mathrm{D}$ levels and liver health. In general, higher ALP levels occur if the bile ducts are obstructed ${ }^{(27)}$ or if bone conditions are present ${ }^{(28)}$. One of the articles showed that ALP levels were higher in consecutive patients with $25(\mathrm{OH}) \mathrm{D}$ concentrations of $\leq 10 \mathrm{nM}^{(29)}$, and the authors speculated that the elevated ALP may be due to increased bone formation. In the present study, we excluded individuals with osteoporosis to some extent to eliminate confounding factors in our analysis.

The relationship and mechanism between vitamin $\mathrm{D}$ deficiency and ALP levels are rarely reported in mouse, rat or cell studies. However, it has been found that adding 
Table 2 Adjusted associations of two models between categories of serum 25-hydroxyvitamin D and abnormal levels of ALT, AST, ALP and GGT, NHANES (2001-2006)

\begin{tabular}{|c|c|c|c|c|c|c|c|c|c|c|c|c|c|}
\hline \multirow[b]{3}{*}{$\begin{array}{l}\text { Population } \\
\text { (numbers) }\end{array}$} & \multirow{3}{*}{$\begin{array}{l}\text { Abnormal } \\
\text { levels of } \\
\text { liver } \\
\text { enzyme* }\end{array}$} & \multicolumn{12}{|c|}{ Serum 25-hydroxyvitamin $\mathrm{D}(25(\mathrm{OH}) \mathrm{D})$} \\
\hline & & \multicolumn{6}{|c|}{ Model† } & \multicolumn{6}{|c|}{ Modelł } \\
\hline & & $\begin{array}{l}\text { Adequate } \\
(>50 \\
\mathrm{nmol} / \mathrm{l})\end{array}$ & $\begin{array}{c}\text { Inadequate } \\
(30-50 \\
\mathrm{nmol} / \mathrm{l})\end{array}$ & & $\begin{array}{c}\text { Deficient } \\
(<30 \mathrm{nmol} / \mathrm{l})\end{array}$ & & $P_{\text {for trend }}$ & $\begin{array}{c}\text { Adequate } \\
(>50 \mathrm{nmol} / \mathrm{l})\end{array}$ & $\begin{array}{l}\text { Inadequate } \\
(30-50 \mathrm{nmol} / \mathrm{l})\end{array}$ & & $\begin{array}{c}\text { Deficient } \\
(<30 \mathrm{nmol} / \mathrm{l})\end{array}$ & & $P_{\text {for trend }}$ \\
\hline \multirow{4}{*}{$\begin{array}{l}\text { All population } \\
(24229)\end{array}$} & ALT & Ref & 1.25 & $1 \cdot 13-1 \cdot 37$ & $1 \cdot 15$ & $0.98-1.34$ & $<0.001$ & Ref & $1 \cdot 12$ & $0.97-1.29$ & 1.00 & $0.78-1.28$ & 0.002 \\
\hline & AST & Ref & $1 \cdot 12$ & $1.01-1.22$ & 1.23 & $1.06-1.42$ & 0.001 & Ref & 1.09 & $0.94-1.26$ & $1 \cdot 11$ & $0.87-1.42$ & 0.203 \\
\hline & ALP & Ref & 1.43 & $1.24-1.65$ & 2.45 & $2.03-2.95$ & $<0.001$ & Ref & 1.41 & $1.12-1.77$ & $2 \cdot 67$ & $1.98-3.59$ & $<0.001$ \\
\hline & GGT & Ref & $1 \cdot 17$ & $1.06-1.30$ & 1.52 & $1.32-1.75$ & $<0.001$ & Ref & 1.05 & $0.90-1.21$ & $1 \cdot 13$ & $0.91-1.41$ & 0.001 \\
\hline \multirow{4}{*}{$\begin{array}{l}\text { Confirmed } \\
\text { healthy } \\
\text { population } \\
(10436)\end{array}$} & ALT & Ref & 1.25 & $1.08-1.45$ & 1.09 & $0.84-1.41$ & 0.001 & Ref & 1.20 & $1.02-1.41$ & 1.11 & $0.84-1.48$ & 0.006 \\
\hline & AST & Ref & 1.05 & $0.91-1.23$ & $1 \cdot 18$ & $0.92-1.51$ & 0.064 & Ref & 1.06 & $0.89-1.26$ & 1.07 & $0.80-1.44$ & 0.418 \\
\hline & ALP & Ref & 1.25 & $1.01-1.55$ & 2.43 & $1.83-3.22$ & $<0.001$ & Ref & 1.32 & $1.03-1.69$ & 3.02 & $2.25-4.07$ & $<0.001$ \\
\hline & GGT & Ref & $1 \cdot 16$ & $1.00-1.34$ & 1.36 & $1.09-1.70$ & $<0.001$ & Ref & 1.22 & $0.91-1.63$ & 1.11 & $0.72-1.71$ & $<0.001$ \\
\hline \multirow{4}{*}{$\begin{array}{l}\text { Non-alcoholic } \\
\text { healthy } \\
\text { population } \\
(8605)\end{array}$} & ALT & Ref & 1.21 & $1.03-1.43$ & 1.05 & $0.79-1.39$ & 0.018 & Ref & $1 \cdot 15$ & $0.94-1.40$ & 1.20 & $0.87-1.66$ & 0.121 \\
\hline & AST & Ref & 1.06 & $0.89-1.26$ & $1 \cdot 13$ & $0.85-1.51$ & 0.101 & Ref & 1.05 & $0.85-1.30$ & $1 \cdot 12$ & $0.79-1.59$ & 0.130 \\
\hline & ALP & Ref & $1 \cdot 19$ & $0.94-1.50$ & $2 \cdot 32$ & $1.71-3.15$ & $<0.001$ & Ref & 1.21 & $0.91-1.60$ & $2 \cdot 28$ & $1.59-3.26$ & 0.003 \\
\hline & GGT & Ref & $1 \cdot 10$ & $0.93-1.30$ & 1.23 & $0.95-1.58$ & 0.002 & Ref & $1 \cdot 10$ & $0.91-1.34$ & 1.29 & $0.97-1.73$ & 0.004 \\
\hline \multirow{4}{*}{$\begin{array}{l}\text { Alcoholic healthy } \\
\text { population } \\
\text { (1338) }\end{array}$} & ALT & Ref & 1.82 & $1.20-2.75$ & 1.95 & $0.96-4.00$ & 0.009 & Ref & 1.54 & $1 \cdot 12-2 \cdot 11$ & 1.27 & $0.69-2.34$ & 0.008 \\
\hline & AST & Ref & 1.22 & $0.84-1.76$ & 1.21 & $0.65-2.24$ & 0.406 & Ref & 1.05 & $0.78-1.42$ & 0.96 & $0.55-1.65$ & 0.443 \\
\hline & ALP & Ref & 1.48 & $0.72-3.03$ & $2 \cdot 20$ & $0.80-6.03$ & 0.11 & Ref & $1 \cdot 15$ & $0.59-2.22$ & 4.76 & $2 \cdot 17-10.43$ & 0.008 \\
\hline & GGT & Ref & 1.45 & $1.00-2 \cdot 12$ & 1.99 & $1.12-3.55$ & 0.008 & Ref & $1 \cdot 12$ & $0.81-1.54$ & 1.09 & $0.65-1.83$ & 0.084 \\
\hline \multirow{4}{*}{$\begin{array}{l}\text { Viral hepatitis } \\
\text { (2996) }\end{array}$} & ALT & Ref & 1.32 & $1.02-1.71$ & 1.15 & $0.77-1.73$ & 0.049 & Ref & 1.36 & $1.04-1.79$ & 1.02 & $0.64-1.61$ & 0.051 \\
\hline & AST & Ref & $1 \cdot 18$ & $0.91-1.54$ & $1 \cdot 12$ & $0.76-1.66$ & 0.666 & Ref & 1.47 & $1.11-1.94$ & 1.34 & $0.87-2.08$ & 0.140 \\
\hline & ALP & Ref & 2.08 & $1.39-3 \cdot 13$ & $2 \cdot 77$ & $1.62-4.72$ & 0.001 & Ref & $2 \cdot 13$ & $1.34-3.39$ & $2 \cdot 87$ & $1.52-5.44$ & 0.006 \\
\hline & GGT & Ref & $1 \cdot 12$ & $0.84-1.50$ & 1.28 & $0.86-1.90$ & 0.398 & Ref & $1 \cdot 21$ & $0.91-1.63$ & 1.13 & $0.72-1.71$ & 0.276 \\
\hline
\end{tabular}

ALP, alkaline phosphatase; AST, aspartate aminotransferase; ALT, alanine aminotransferase; GGT, gamma-glutamyl transaminase; NHANES, National Health and Nutrition Examination Survey.

*Defined as $>47 \mathrm{IU} / \mathrm{l}$ in men or $>30 \mathrm{IU} / \mathrm{l}$ in women for ALT, $>33 \mathrm{IU} / \mathrm{I}$ in men and women for AST, $>113 \mathrm{IU} / \mathrm{l}$ in men and women for ALP and $>65 \mathrm{IU} / \mathrm{l}$ in men or $>36 \mathrm{IU} / \mathrm{l}$ in women for GGT.

†Adjusted for age (continuous), gender (male, female), race and ethnicity (Mexican American, other Hispanic, non-Hispanic White, non-Hispanic Black and other).

†Adjusted for age (continuous), gender (male, female), race and ethnicity (Mexican American, other Hispanic, non-Hispanic White, non-Hispanic Black and other), education (<9th grade, 9-11th grade, high school graduate/GED, some college or

AA degree, college graduate or above), poverty:income ratio ( $\leq 1$ and $>1)$, BMI ( $<25,25-30$ and $\left.>30 \mathrm{~kg} / \mathrm{m}^{2}\right)$, alcohol use $(0,0.01-4 \cdot 9,5-14 \cdot 9,15-29 \cdot 9$ and $\geq 30)$ and cotinine level $(<0.01 \mathrm{ng} / \mathrm{ml}(\mathrm{LOD}), 0.01-10 \mathrm{ng} / \mathrm{ml}$ and $>10 \mathrm{ng} / \mathrm{ml})$. 


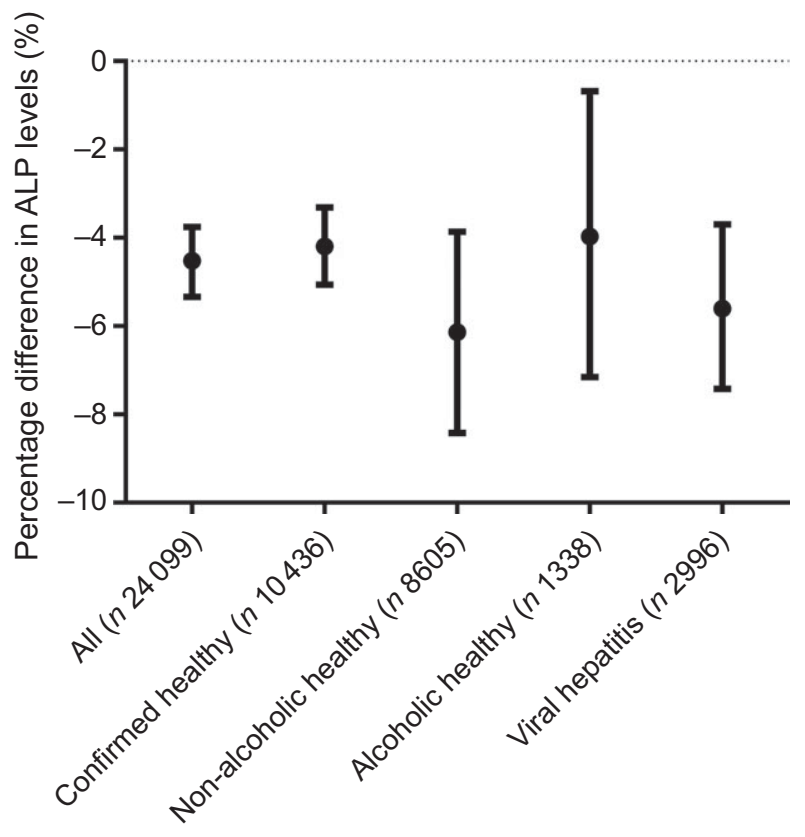

Fig. 3 For each doubling to tripling (interquartile ratio contrast) in serum vitamin $D$ levels, the percentage difference in alkaline phosphatase (ALP) levels in the various groups

vitamin D to cells can increase ALP activity ${ }^{(30,31)}$. In addition, supplementation of $1 \alpha, 25(\mathrm{OH}) \mathrm{D}$ (3) could increase ALP concentrations in mice with low ALP levels ${ }^{(32)}$. More mechanism studies are needed to explore the relationship between vitamin D deficiency and ALP concentrations.

In the present study, we found strong associations between vitamin D deficiency and higher ALP levels in individuals with viral hepatitis. Petta et al. reported that chronic hepatitis $\mathrm{C}$ subjects had low 25(OH)D serum concentrations as well as decreased expression of cytochrome P450, family 27, subfamily A, polypeptide 1 (CYP27A1) ${ }^{(33)}$. Furthermore, scientists discovered that vitamin D supplementation in patients with hepatitis $\mathrm{C}$ virus could improve the viral response ${ }^{(34)}$. Therefore, low serum 25(OH)D levels may be associated with the occurrence of viral hepatitis. Notably, our study suggests that ALP may play an important role in hepatitis caused by vitamin D deficiency.

In our study, we found no interaction between alcohol consumption and ALP. However, alcohol has side effects on the liver. It has been found that there is a significant interaction between Mn exposure and alcohol consumption in the relationship between Mn exposure and liver function $^{(35)}$. Although no interaction was observed in our results, the reason may be the small number of cases ( $n 38,2 \cdot 8 \%$ ) in the alcoholic healthy population; however, the number of cases of abnormal levels of ALP in other populations varies from 4.4 to $4.9 \%$, which may induce low statistical power for inference. This phenomenon indicates that the number of people who drink alcohol with abnormal ALP levels is less than that of other subgroups, suggesting that there is a negative association between alcohol consumption and ALP, which is supported by previous studies $^{(36,37)}$, although other studies have found no association between alcohol and ALP levels ${ }^{(38,39)}$. Further studies are needed with a larger sample size to demonstrate this association.

This study has some critical strengths. A large and representative sample of the US population ensures the reliability of the results. Moreover, the inverse relationships between serum 25(OH)D levels and ALP remained after adjusting for confounders related to liver disease, including smoking, alcohol drinking, obesity and hepatitis $\mathrm{B}$ and $\mathrm{C}$ infection.

There are several limitations to our study. First, because of the cross-sectional nature of the present study, we could not determine whether $25(\mathrm{OH}) \mathrm{D}$ levels affect ALP concentrations or vice versa. Second, although we adjusted for potential covariates, residual contributing factors remain a possibility, such as genetic predisposition.

\section{Conclusions}

In summary, we found evidence of an inverse association between serum vitamin D and serum ALP levels in the US general population, and the correlation was strong among individuals who had viral hepatitis. These findings suggest the need for an ongoing evaluation of the possible protective role of vitamin D supplementation for liver function. Future studies are needed to confirm these findings and to explore the potential mechanisms.

\section{Acknowledgements}

Acknowledgements: N/A. Financial support: N/A. Conflict of interest: None declared. Authorship: J.T., C.X. and Y.J.S. contributed to the conception and design of the study. C.X. performed the analyses and drafted the manuscript. The major contribution for writing of the manuscript was from X.W.H. and C.X. Y.J.S., Z.H.L. and X.Z.F. helped in drafting the manuscript. All authors approved the final manuscript. Ethics of buman subject participation: This study was conducted according to the guidelines laid down in the Declaration of Helsinki, and all procedures involving research study participants were approved by the National Center for Health Statistics Research Ethics Review Board. Written informed consent was obtained from all subjects.

\section{Supplementary material}

For supplementary material accompanying this paper visit https://doi.org/10.1017/S1368980020000348

\section{References}

1. DeLuca HF \& Schnoes HK (1976) Metabolism and mechanism of action of vitamin D. Ann Rev Biochem 45, 631-666.

2. Lips P (2001) Vitamin D deficiency and secondary hyperparathyroidism in the elderly: consequences for bone loss and fractures and therapeutic implications. Endocr Rev 22, 477-501. 
3. Lavie CJ, Dinicolantonio JJ, Milani RV et al. (2013) Vitamin D and cardiovascular health. Circulation 128, 2404-2406.

4. Pittas AG, Lau J, Hu FB et al. (2007) The role of vitamin D and calcium in type 2 diabetes. A systematic review and metaanalysis. J Clin Endocrinol Metab 92, 2017-2029.

5. Ford ES, Ajani UA, McGuire LC et al. (2005) Concentrations of serum vitamin $\mathrm{D}$ and the metabolic syndrome among U.S. adults. Diabetes Care 28, 1228-1230.

6. Holick MF (2004) Vitamin D: importance in the prevention of cancers, type 1 diabetes, heart disease, and osteoporosis. Am J Clin Nutr 79, 362-371.

7. Arteh J, Narra S \& Nair S (2010) Prevalence of vitamin D deficiency in chronic liver disease. Dig Dis Sci 55, 2624-2628.

8. Stokes CS, Volmer DA, Grunhage F et al. (2013) Vitamin D in chronic liver disease. Liver Int 33, 338-352.

9. Barchetta I, Angelico F, Del Ben M et al. (2011) Strong association between nonalcoholic fatty liver disease (NAFLD) and low $25(\mathrm{OH})$ vitamin D levels in an adult population with normal serum liver enzymes. BMC $\operatorname{Med} \mathbf{9}, 85$.

10. Targher G, Bertolini L, Scala L et al. (2007) Associations between serum 25-hydroxyvitamin D3 concentrations and liver histology in patients with non-alcoholic fatty liver disease. Nutr Metab Cardiovasc Dis 17, 517-524.

11. National Center for Health Statistics (2015) National Health and Nutrition Examination Survey 1999-2010 questionnaires, datasets, and related documentation. http://wwwcdcgov/ nchs/nhanes/nhanes_questionnaireshtm (accessed November 2015).

12. Xu C, Liu Q, Zhang Q et al. (2015) Urinary enterolactone associated with liver enzyme levels in US adults: national Health and Nutrition Examination Survey (NHANES). Br J Nutr 114, 91-97.

13. Xu C, Liu Q, Zhang Q et al. (2015) Urinary enterolactone is associated with obesity and metabolic alteration in men in the US National Health and Nutrition Examination Survey 2001-10. Br J Nutr 113, 683-690.

14. Analytical Note for 25-Hydroxyvitamin D Data Analysis using NHANES III (1988-1994) N-, and NHANES 20072010. https://wwwncdcgov/nchs/nhanes/vitamind/analytical noteaspx?h=/Nchs/Nhanes/2005-2006/VID_Dhtm\&t=VID_D \%20Doc- (accessed October 2015).

15. National Center for Health Statistics, Centers for Disease Control and Prevention (2010) Archived Vitamin D RIA-harmonized Data Files and Documentation. https://wwwn.cdc.gov/nchs/ nhanes/vitamind/RiaMethod.aspx (accessed June 2020).

16. Committee to Review Dietary Reference Intakes for Vitamin D and Calcium IoM (2011) Implications and special concerns: conclusions about vitamin D deficiency in the United States and Canada. In Dietary Reference Intakes for Calcium and Vitamin D, p. 487 [AC Ross, CL Taylor, AL Yaktine et al., editors]. Washington, DC: National Academies Press.

17. Xiao Q, Sinha R, Graubard BI et al. (2014) Inverse associations of total and decaffeinated coffee with liver enzyme levels in National Health and Nutrition Examination Survey 1999-2010. Hepatology 60, 2091-2098.

18. Nadeem Saqib MA, Rafique I, Hayder I et al. (2018) Comparison of vitamin D levels with bone density, calcium, phosphate and alkaline phosphatase - an insight from major cities of Pakistan. J Pak Med Assoc 68, 543-547.

19. Naderpoor N, Mousa A, de Courten M et al. (2018) The relationship between 25-hydroxyvitamin D concentration and liver enzymes in overweight or obese adults: cross-sectional and interventional outcomes. J Steroid Biochem 177, 193-199.

20. Mansour-Ghanaei F, Pourmasoumi M, Hadi A et al. (2019) The efficacy of vitamin D supplementation against nonalcoholic fatty liver disease: a meta-analysis. J Diet Suppl 1, 1-19.

21. Al Alwan I, Al Badi M, Badri M et al. (2019) Higher serum alkaline phosphatase activity in infants born to vitamin Ddeficient mothers. Arch Osteoporos 14, 102.
22. Jesudason D, Need AG, Horowitz M et al. (2002) Relationship between serum 25-hydroxyvitamin D and bone resorption markers in vitamin D insufficiency. Bone 31, 626-630.

23. Welz T, Childs K, Ibrahim F et al. (2010) Efavirenz is associated with severe vitamin D deficiency and increased alkaline phosphatase. AIDS 24, 1923-1928.

24. Martin-Carbonero L, Nunez M, Gonzalez-Lahoz J et al. (2003) Incidence of liver injury after beginning antiretroviral therapy with efavirenz or nevirapine. HIV Clin Trials $\mathbf{4}$, $115-120$.

25. Sulkowski MS, Thomas DL, Mehta SH et al. (2002) Hepatotoxicity associated with nevirapine or efavirenzcontaining antiretroviral therapy: role of hepatitis C and B infections. Hepatology 35, 182-189.

26. Cassetti I, Madruga JV, Suleiman JM et al. (2007) The safety and efficacy of tenofovir DF in combination with lamivudine and efavirenz through 6 years in antiretroviral-naive HIV-1infected patients. HIV Clin Trials 8, 164-172.

27. Kaplan MM \& Righetti A (1970) Induction of rat liver alkaline phosphatase: the mechanism of the serum elevation in bile duct obstruction. J Clin Invest 49, 508-516.

28. Garnero P \& Delmas PD (1993) Assessment of the serum levels of bone alkaline phosphatase with a new immunoradiometric assay in patients with metabolic bone disease. J Clin Endocrinol Metab 77, 1046-1053.

29. Need AG, O'Loughlin PD, Morris HA et al. (2008) Vitamin D metabolites and calcium absorption in severe vitamin D deficiency. J Bone Miner Res 23, 1859-1863.

30. Xiong Y, Zhang Y, Xin N et al. (2017) 1alpha,25Dihydroxyvitamin D3 promotes osteogenesis by promoting Wnt signaling pathway. J Steroid Biochem 174, 153-160.

31. Ozeki K, Aoki H \& Fukui Y (2008) The effect of adsorbed vitamin $\mathrm{D}$ and $\mathrm{K}$ to hydroxyapatite on ALP activity of MC3T3-E1 cell. J Mater Sci Mater Med 19, 1753-1757.

32. Poon CC, Li RW, Seto SW et al. (2015) In vitro vitamin K(2) and 1alpha,25-dihydroxyvitamin D(3) combination enhances osteoblasts anabolism of diabetic mice. Eur J Pharmacol 767 , $30-40$.

33. Petta S, Camma C, Scazzone C et al. (2010) Low vitamin D serum level is related to severe fibrosis and low responsiveness to interferon-based therapy in genotype 1 chronic hepatitis C. Hepatology 51, 1158-1167.

34. Abu-Mouch S, Fireman Z, Jarchovsky J et al. (2011) Vitamin D supplementation improves sustained virologic response in chronic hepatitis C (genotype 1)-naive patients. World J Gastroenterol 17, 5184-5190.

35. Deng Q, Liu J, Li Q et al. (2013) Interaction of occupational manganese exposure and alcohol drinking aggravates the increase of liver enzyme concentrations from a crosssectional study in China. Environ Health 12, 30.

36. Tolstrup JS, Gronbaek M, Tybjaerg-Hansen A et al. (2009) Alcohol intake, alcohol dehydrogenase genotypes, and liver damage and disease in the Danish general population. $\mathrm{Am} \mathrm{J}$ Gastroenterol 104, 2182-2188.

37. Rex KF, Krarup HB, Laurberg P et al. (2016) Liver biochemistry and associations with alcohol intake, hepatitis B virus infection and Inuit ethnicity: a population-based comparative epidemiological survey in Greenland and Denmark. Int J Circumpolar Health 75, 29528.

38. Gluud C, Andersen I, Dietrichson O et al. (1981) Gammaglutamyltransferase, aspartate aminotransferase and alkaline phosphatase as markers of alcohol consumption in outpatient alcoholics. Eur J Clin Invest 11, 171-176.

39. Shimizu Y, Nakazato M, Sekita T et al. (2013) Association between alkaline phosphatase and hypertension in a rural Japanese population: the Nagasaki Islands study. J Physiol Anthropol 32, 10. 